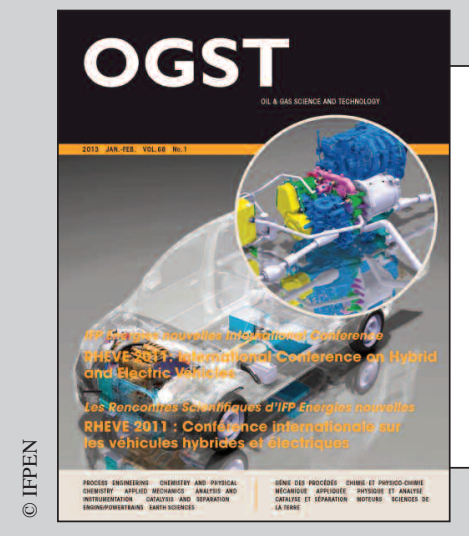

Dossier

This paper is a part of the hereunder thematic dossier published in OGST Journal, Vol. 68, No. 1, pp. 3-178 and available online here

Cet article fait partie du dossier thématique ci-dessous publié dans la revue OGST, Vol. 68, n 1 , pp. 3-178 et téléchargeable ici

DOSSIER Edited by/Sous la direction de : A. Sciarretta, F. Badin et J. Bernard RHEVE 2011 : International Conference on Hybrid and Electric Vehicles RHEVE 2011 : Conférence internationale sur les véhicules hybrides et électriques

Oil \& Gas Science and Technology - Rev. IFP Energies nouvelles, Vol. 68 (2013), No. 1, pp. 3-178

Copyright (C) 2013, IFP Energies nouvelles

\section{$3>$ Editorial}

$13>$ Analysis and Experimental Implementation of a Heuristic Strategy for Onboard Energy Management of a Hybrid Solar Vehicle

Analyse et expérimentation d'une stratégie heuristique pour la gestion d'énergie à bord d'un véhicule hybride solaire

G. Coraggio, C. Pisanti, G. Rizzo and M. Sorrentino

23 > Open Issues in Supervisory Control of Hybrid Electric Vehicles: A Unified Approach Using Optimal Control Methods

Questions ouvertes sur la supervision énergétique des véhicules hybrides électriques : une approche unifiée par la théorie de la commande optimale

L. Serrao, A. Sciarretta, 0. Grondin, A. Chasse, Y. Creff, D. Di Domenico, P. Pognant-Gros, C. Querel and L. Thibault

35 > Optimization of Hybrid Power Trains by Mechanistic System Simulations

Optimisation de groupes motopropulseurs électriques hybrides par simulation du système mécanique

T. Katrašnik and J.C. Wurzenberger

51 > A Phenomenological Heat Transfer Model of SI Engines - Application to the Simulation of a Full-Hybrid Vehicle

Un modèle phénoménologique de transfert thermique au sein de moteurs à allumage commandé - Application à la simulation d'un véhicule full-hybride

R. Dubouil, J.-F. Hetet and A. Maiboom

$65>$ Battery Electric Vehicle (BEV) or Range Extended Electric Vehicle (REEV)? - Deciding Between Different Alternative Drives Based on Measured Individual Operational Profiles

Véhicule électrique à batteries (BEV) ou véhicule électrique à prolongateur d'autonomie (REEV) ? - Choisir entre différents entrânements alternatifs sur la base de profils opérationnels individuels mesurés

S. Marker, B. Rippel, P. Waldowski, A. Schulz and V. Schindler

$79>$ Assessment by Simulation of Benefi ts of New HEV Powertrain Configurations

Évaluation par simulation des bénéfi ces de nouvelles chaînes de traction hybrides

N. Kim and A. Rousseau
95 > Dual Mode Vehicle with In-Wheel Motor: Regenerative Braking Optimization

Véhicule bi-mode avec moteurs roues : optimisation du freinage récupératif

G. Le Solliec, A. Chasse, J. Van-Frank and D. Walser

109 > Engine Downsizing and Electric Hybridization Under Consideration of Cost and Drivability

Réduction de taille moteur et hybridation électrique avec considérations de coût et de performance de conduite

S. Ebbesen, P. Elbert and L. Guzzella

117 > Representative Midwestern US Cycles: Synthesis and Applications Cycles représentatifs du Middle West américain : synthèse et applications

T.-K. Lee and Z.S. Filipi

127 > A Review of Approaches for the Design of Li-lon BMS Estimation Functions

Revue de différentes approches pour l'estimation de l'état de charge de batteries Li-ion

D. Di Domenico, Y. Creff, E. Prada, P. Duchêne, J. Bernard and V. Sauvant-Moynot

137 > Experimental Assessment of Battery Cycle Life Within the SIMSTOCK Research Program

Évaluation expérimentale de la durée de vie de la batterie dans le programme de recherche SIMSTOCK

P. Gyan, P. Aubret, J. Hafsaoui, F. Sellier, S. Bourlot, S. Zinola and F. Badin

$149>$ Smart Battery Thermal Management for PHEV Efficiency Une gestion avancée de la thermique de la batterie basse tension de traction pour optimiser l'efficacité d'un véhicule hybride électrique rechargeable

L. Lefebvre

$165>$ Parameterization and Observability Analysis of Scalable Battery Clusters for Onboard Thermal Management

Paramétrage et analyse d'observabilité de clusters de batteries de taille variable pour une gestion thermique embarquée

Xinfan Lin, Huan Fu, Hector E. Perez, Jason B. Siege, Anna G. Stefanopoulou, Yi Ding and Matthew P. Castanier 


\title{
Analysis and Experimental Implementation of a Heuristic Strategy for Onboard Energy Management of a Hybrid Solar Vehicle
}

\author{
G. Coraggio, C. Pisanti* , G. Rizzo and M. Sorrentino \\ Department of Industrial Engineering, University of Salerno - Italy \\ e-mail: gcoraggio@unisa.it - cpisanti@unisa.it - grizzo@unisa.it - msorrentino@unisa.it \\ * Corresponding author
}

\begin{abstract}
Résumé - Analyse et expérimentation d'une stratégie heuristique pour la gestion d'énergie à bord d'un véhicule hybride solaire - $\mathrm{Ce}$ document présente l'analyse et la mise en œuvre d'expérimentation de règles bases RB (Rule Base) de stratégie de contrôle pour la gestion d'énergie à bord d'un véhicule hybride solaire HSV (Hybrid Solar Vehicle) qui est constitué d'un véhicule hybride électrique fabriqué en série et alimenté par des panneaux photovoltaïques. La stratégie RB se compose de deux tâches : l'une externe, qui détermine l'état final de charge de la batterie (SOC, State of Charge) qui doit être atteint à la fin du cycle de conduite pour permettre la pleine exploitation de l'énergie solaire pendant la phase de stationnement, l'autre interne, dont le but est de définir le générateur électrique optimal (ICEEG, Internal Combustion Engine - Electric Generator), la trajectoire de la puissance et l'oscillation du SOC autour de la valeur finale. Cette stratégie de contrôle a été mise en œuvre en temps réel dans une unité de contrôle $\mathrm{NI}^{\circledR}$ cRIO (National Instruments compact RIO), permettant ainsi d'effectuer des essais expérimentaux pour la validation de la gestion d'énergie sur un prototype réel HSV développé par l'Université de Salerne.
\end{abstract}

Abstract - Analysis and Experimental Implementation of a Heuristic Strategy for Onboard Energy Management of a Hybrid Solar Vehicle - This paper focuses on the simulation analysis and the experimental implementation of a Rule-Based $(R B)$ control strategy for on-board energy management of a Hybrid Solar Vehicle (HSV), consisting in a series hybrid electric vehicle assisted by photovoltaic panels. The RB strategy consists of two tasks: one external, which determines the final battery State of Charge (SOC) to be reached at the end of the driving schedule to allow full exploitation of solar energy during parking phase; the other internal, whose aim is to define the optimal Electric Generator (ICE-EG) power trajectory and SOC oscillation around the final value. This control strategy has been implemented in a real time $N I^{\circledR} c R I O$ control unit, thus allowing to perform experimental tests for energy management validation on a real HSV prototype developed at the University of Salerno. 


\section{ACRONYMS}

$\begin{array}{ll}\text { EG } & \text { Electric Generator } \\ E_{\text {sun }, \text { day }} & \text { Daily solar energy } \\ E_{\text {sun }, p} & \text { Solar energy during parking phases } \\ \text { HEV } & \text { Hybrid Electric Vehicle } \\ \text { HSV } & \text { Hybrid Solar Vehicle } \\ \text { ICE } & \text { Internal Combustion Engine } \\ \text { NI® cRIO } & \text { National Instruments compact RIO } \\ \text { RB } & \text { Rule-Based } \\ \text { SOC } & \text { State of Charge } \\ P_{E G} & \text { Power of the electric generator } \\ P_{E M} & \text { Power of the electric motor } \\ S_{f} & \text { Sun factor }\end{array}$

\section{INTRODUCTION}

In the last years, there is an increasing awareness about the need to achieve a more sustainable mobility, allowing meeting the mobility needs of the present without compromising the ability of future generations to meet their needs [1]. The most pressing arguments towards new solutions for personal mobility are the following:

- proved reserves of oil, largely used for car propulsion, will end in about 45 years at the actual consumption rate [2]; moreover, oil price is subject to large and unpredictable fluctuations (Fig. 1);

- the $\mathrm{CO}_{2}$ generated by the combustion processes occurring in conventional thermal engines contributes to the greenhouse effects, with dangerous and maybe dramatic effects on global warming and climatic changes;

- the worldwide demand for personal mobility is rapidly growing, especially in China and India; as a consequence, energy consumption and $\mathrm{CO}_{2}$ emissions related to cars and transportation are increasing.

One of the most realistic short term solutions to the reduction of gaseous pollution in urban drive, as well as the energy saving requirements, is represented by Hybrid Electric Vehicles (HEV) [3-5]. These vehicles that have evolved to industrial maturity allow achieving significant benefits in terms of fuel economy but still using fossil fuels. On the other hand, in recent years increasing attention is being spent towards the applications of solar energy to electric and also to hybrid cars [6]. But, while pure solar vehicles do not represent a practical alternative to cars for normal use, the concept of a hybrid electric car assisted by solar panels appears more realistic. The reasons for studying and developing a Hybrid Solar Vehicle (HSV) can be therefore summarized as follows:

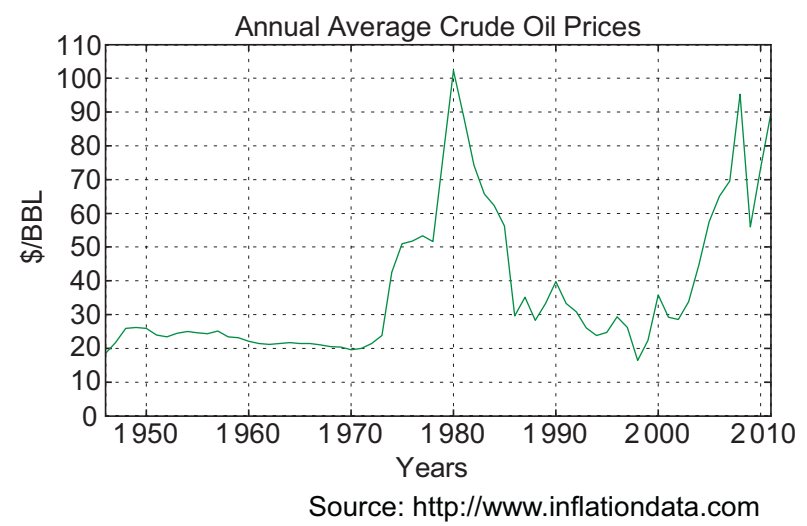

Figure 1

Trends in oil price.

- solar energy is renewable, free and largely diffused, and photovoltaic panels are subject to continuous technological advances in terms of cell efficiency [7]; their diffusion is rapidly growing, while their cost exhibits in last years a marked decreasing trend [8];

- solar cars, in spite of some spectacular outcomes in competitions as World Solar Challenge [9], do not represent a practical alternative to conventional cars, due to limitations on maximum power, range, dimensions and costs;

- there is the possibility of fruitfully combining HEV and solar power related energetic benefits $[6,9]$.

A considerable research has been carried out in last decades about the energy management and control of hybrid vehicles $[3,10]$. Most of the papers focus on parallel hybrid vehicles, while some techniques can be applied both to parallel and series hybrid. Regard to series hybrid, different Rule-Based (RB) methods were studied. Both switching logic control for battery recharge [11] and Fuzzy-Logic methods [12] were proposed. Load-leveling approach, consisting on a method of forcing the engine to operate near the peak efficiency region, has been also studied [13]. More complex approaches, based on optimal control and on application of Pontyragin maximum principle, were also proposed for series hybrid vehicles [13-16].

In next chapters, the RB control strategy applied on the HSV prototype, developed at the University of Salerno [17], is presented. The convenience of this strategy has been first analyzed by simulation analysis, through a model developed in MATLAB ${ }^{\circledR}$. Then, the strategy was implemented in the real-time programmable controller CompactRIO (cRIO) by means of the National 
Instrument $^{\circledR}$ (NI) LabVIEW ${ }^{\circledR}$ graphical programming language. Some preliminary experimental tests are presented at the end of the paper to highlight the suitability of NI cRIO to perform on-board energy management of series HSV by means of the RB strategy developed in [17].

It is worth remarking here that the experimental assessment of real-time implementability and costeffectiveness of supervisory control policies for series hybrid vehicle architectures is a significant contribution to the field, as demonstrated by the not so extended literature on series HEV experimental testing [18-22].

\section{RULE-BASED CONTROL STRATEGY APPLIED TO AN HSV PROTOTYPE}

The RB strategy for a HSV with series structure consists of two tasks, external and internal, respectively [21]:

- the external task determines the final battery State of Charge $\left(S O C_{f}\right)$ to be reached at the end of the driving schedule. $S O C_{f}$ allows full exploitation of solar energy during parking phase (i.e. $E_{\text {sun }, p}$ );

- the internal task estimates: i) the average power of the Electric Generator $P_{E G}$, delivered by ICE-EG and ii) SOC deviation $(\mathrm{SSOC})$ from $S O C_{f}$, as a function of the average power required for traction. The map (Eq. 3) determines the limits of variation of SOC around its final value $S O C_{f}$. It is timely to remark that $d S O C$ does not represent the instantaneous SOC variation but the limit values where the engine/generator group is set on or off (a sort of thermostatic control with variable range).

The overall RB control architecture consists of three look-up tables:

$$
\begin{gathered}
S O C_{f}=f\left(E_{\text {sun }, p}\right) \\
P_{E G}=f\left(\bar{P}_{E M}\right) \\
d S O C=f\left(\bar{P}_{E M}\right)
\end{gathered}
$$

The look-up tables (2) and (3) are determined off-line via optimization analysis, as a function of the average vehicle power demand $P_{E M}$. The best values are determined using a detailed vehicle dynamical model, considering also the effects of thermal transients (due to start-stop operation) on fuel consumption and of the energy required for starting the engine [21-24]. For each condition, a constant vehicle power demand was simulated, and the best combination of $P_{E G}$ and $d S O C$ were determined via mathematical optimization. The actual values of $P_{E G}$ and $d S O C$ were then obtained on-board via interpolation techniques from the optimal values.

The final value of SOC in Equation (1) is obtained as a function of the expected incoming solar energy in next parking phase $[25,26]$. In fact, working with SOC values of 0.6-0.7 allows to minimize battery losses and fuel consumption during driving but also reduces the energy that could be captured for free in next parking phase. On the other hand, the use of an unnecessary low value of $S O C_{f}$ increases battery losses during vehicle operation. The estimation of the incoming solar energy, also by using real-time weather forecast [25], allows to select the most appropriate $S O C_{f}$ value.

Previous studies have shown that the optimal power $P_{E G}$ delivered by ICE-EG is strongly dependant on required power (2), and therefore can differ substantially from the conditions of engine minimum fuel consumption [21]. This implementable RB strategy has been validated against a benchmark strategy obtained off-line via Dynamic Programming [24] and via Genetic Algorithms [23], showing that very limited decay of fuel economy was obtained, even with the use of a posteriori estimate of traction power. The benefits obtainable by using onboard weather forecast for the estimation of final SOC (Eq. I) have also been assessed [23-25, 26].

The RB control strategy has been applied to a HSV prototype, developed at University of Salerno [9], whose main technical specifications are given in Table 1 .

A yearly average value of $4.31 \mathrm{kWh} / \mathrm{m}^{2}$ for the daily solar energy $\bar{E}_{\text {sun,day }}$ irradiating on an horizontal surface was assumed.

Fuel economy was evaluated considering three different scenarios, as shown in Table 2.

Each scenario was analyzed on a $860 \mathrm{~s}$ long driving cycle (Fig. 2). The impact of solar energy contribution also was investigated by varying the sun factor $S_{f}$ in the range $(0 \div 1.5)$, where $S_{f}=1$ corresponds to the average daily energy that impacts on an horizontal surface at the University of Salerno region $\left(4.31 \mathrm{kWh} / \mathrm{m}^{2}\right)$.

TABLE 1

HSV prototype specifications

\begin{tabular}{l|c}
\hline \multicolumn{1}{c|}{ HSV specifications } & \\
\hline Nominal ICE-EG power $(\mathrm{kW})$ & 6 \\
\hline Fuel & Gasoline \\
\hline EM peak power $(\mathrm{kW})$ & 15 \\
\hline Number of Lead-acid battery modules & 16 \\
\hline Battery capacity $(\mathrm{kWh})$ & 17 \\
\hline PV horizontal surface $\left(\mathrm{m}^{2}\right)$ & 1.44 \\
\hline PV efficiency & 0.10 \\
\hline Weight $(\mathrm{kg})$ & 1900 \\
\hline
\end{tabular}


TABLE 2

Simulated control policy scenarios

\begin{tabular}{l|l}
\hline Scenario & \multicolumn{1}{c}{ Characteristics } \\
\hline 1 & $\begin{array}{l}\text { RB strategy: } P_{E G} \text { and } d S O C \text { are obtained by } \\
\text { Equations (2) and (3) }\end{array}$ \\
\hline 2 & $\begin{array}{l}\text { Parametric analysis with } d S O C \text { obtained by } \\
\text { Equation (3) and } P_{E G} \text { variable in the range } \\
(0.25 \div 0.75) \text { times the nominal EG power }(\text { i.e. } 6 \mathrm{~kW}, \\
\text { as shown in } T a b .1)\end{array}$ \\
\hline 3 & $\begin{array}{l}\text { Parametric analysis with } d S O C \text { variable in the range } \\
(0.01 \div 0.02) \text { and } P_{E G} \text { obtained by Equation (2) }\end{array}$ \\
\hline
\end{tabular}
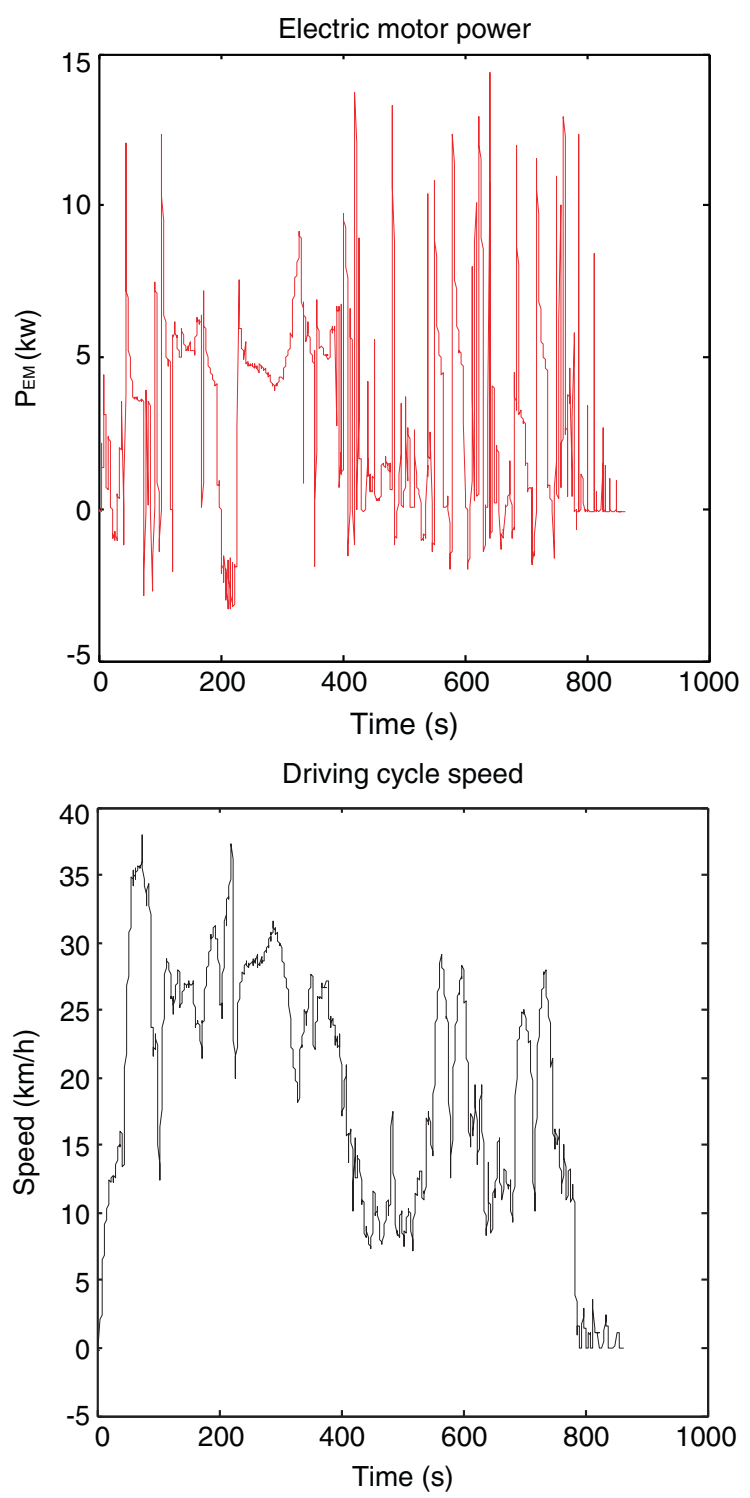

Figure 2

Electric motor power and speed of the considered driving cycle.

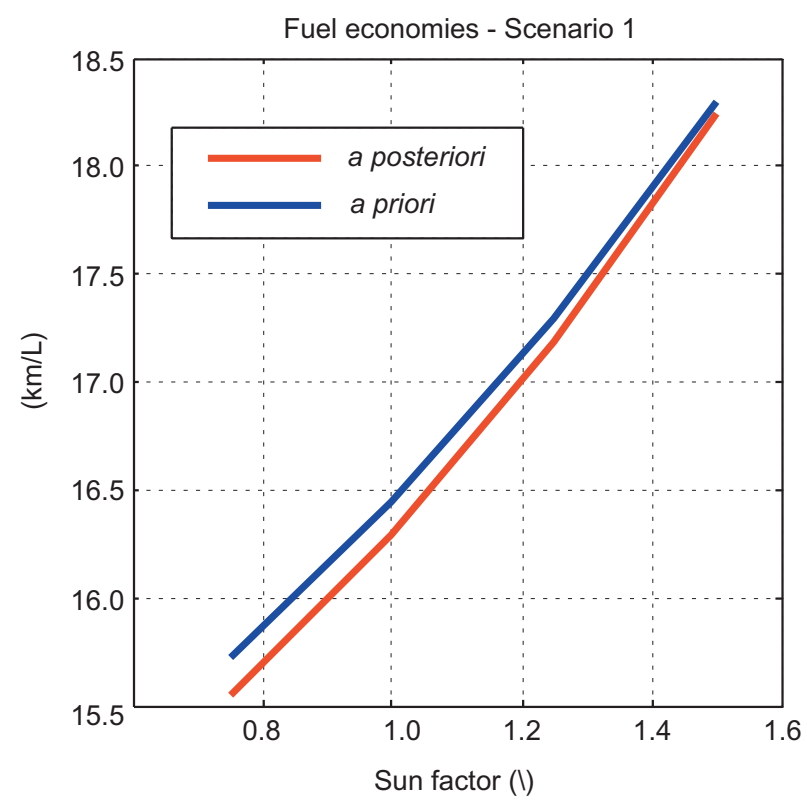

Figure 3

Fuel economy with RB strategy (scenario 1).

In scenario 1 (RB strategy fully active, Tab. 2) fuel economy was simulated assuming both a priori and a posteriori knowledge of average power to be supplied by the series powertrain to the electric motor EM to meet driving cycle demands.

A priori strategy consists in estimating future power values with suitable methodologies (i.e. recurrent neural networks [20,27]) while in case of an a posteriori strategy past values of power are used to estimate the current reference power. In this case, perfect a priori knowledge of power values has been assumed as benchmark for $a$ priori strategy. As expected (Fig. 3), fuel economy values with a posteriori strategy are slightly lower than the ones obtained with a priori strategy. This result is in accordance with the conclusions of previous studies [21, 23], showing that the proposed RB strategy exhibits limited sensitivity to the method of power estimation, and that acceptable results can be achieved also with a simple $a$ posteriori strategy.

In Figures 4 and 5 fuel economy was computed considering scenario 2 and scenario 3 assumptions, respectively (Tab. 2).

The results in Figures 4 and 5 show that fuel economy is rather sensitive to generator power $P_{E G}$, while the sensitivity to $d S O C$ is much lower. In this case (i.e. with this driving cycle) the best fuel economy is obtained with $P_{E G} / P_{\text {EGnom }}=0.75$ and $d S O C=0.016$. Moreover, 


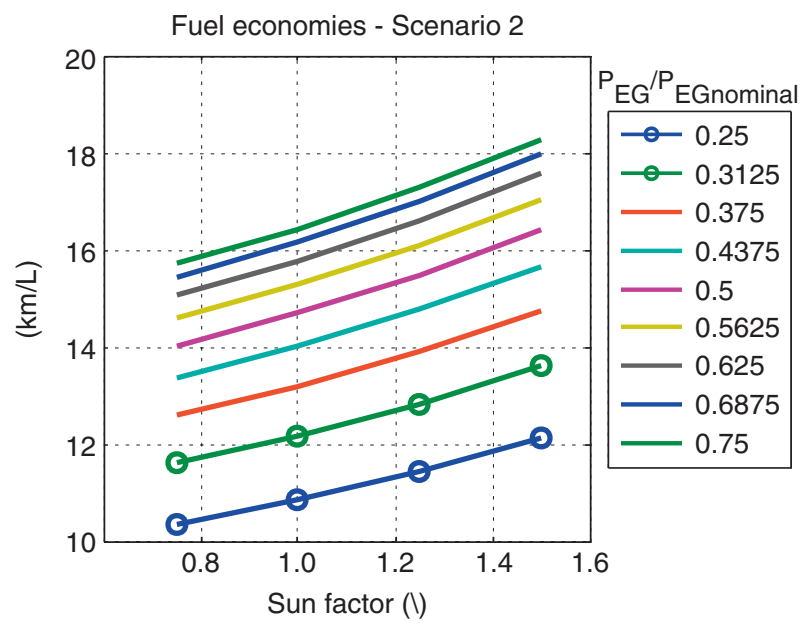

Figure 4

Fuel economy for scenario 2.

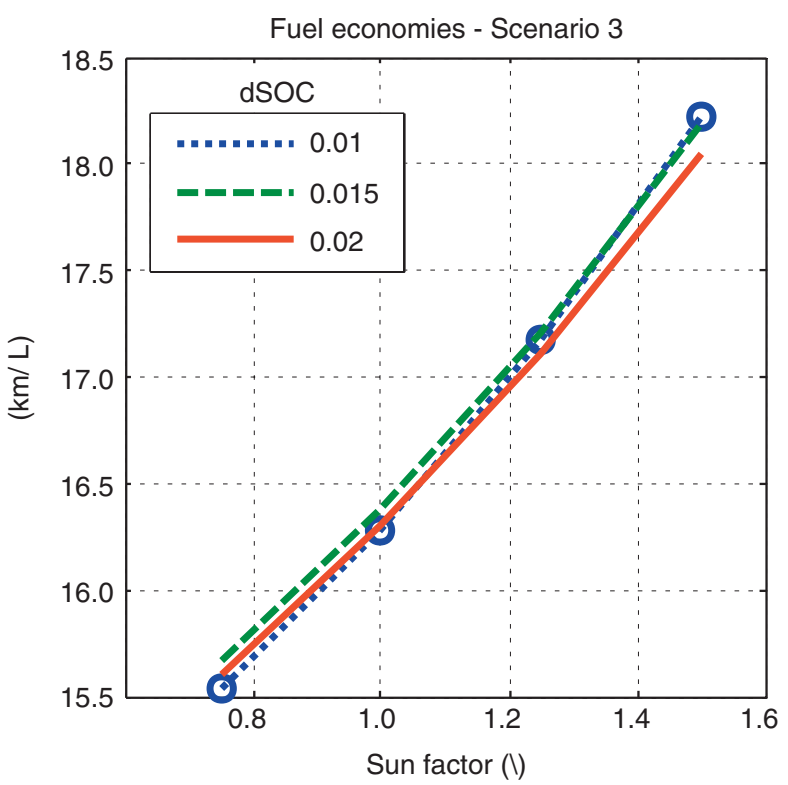

Figure 5

Fuel economy for scenario 3.

while fuel economy of course increases with sun factor, the best combination of $P_{E G}$ and $d S O C$ is rather independent of it.

To check the convenience in adopting the RB strategy, the fuel consumption obtained in scenario 1 and the most convenient cases in scenario 2 and 3 have been compared (Fig. 6). It emerges that even though RB does not achieve the highest fuel economy, its values always

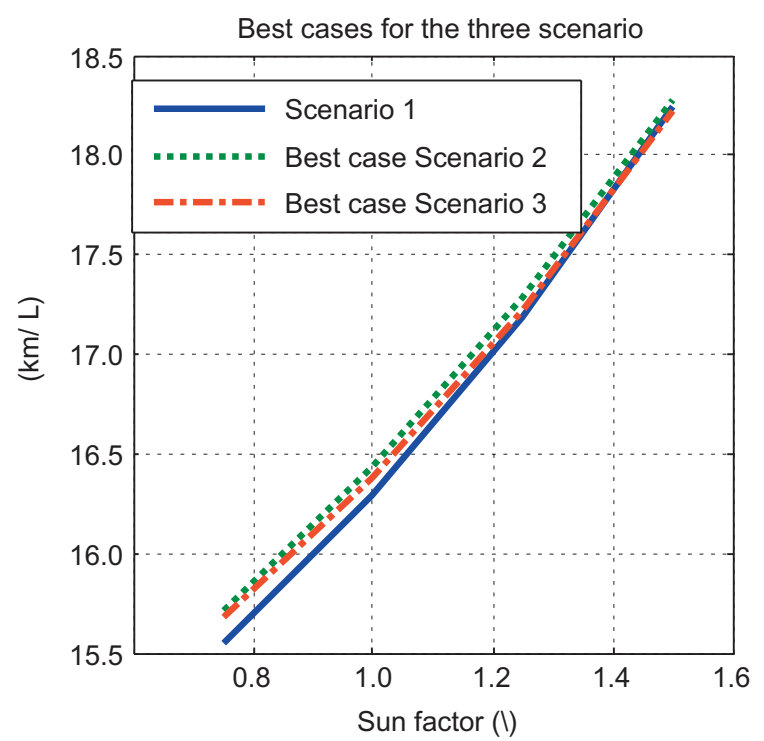

Figure 6

Fuel economies in the three different scenarios.

fall very close to the best ones computed in scenario 2 and scenario 3 .

Therefore, it emerges that strategy of scenario 1, which is implementable on-board, has given almost the same results of the best cases of scenarios 2 and 3, which have been determined off-line after a comparison of simulation results with other cases and therefore are not implementable on-board (in other words, their best results would depend on driving cycle). The fact that scenario 1 is not necessarily the best is consistent with the fact that the proposed strategy is not optimal but heuristic. This result is therefore not a 'proof' of optimality but rather a further confirmation of suitability of the proposed strategy. In fact, a more rigorous approach has been followed in previous papers, where the Rule-Based strategy has been compared with the results of Dynamic Programming, used as a benchmark. The results demonstrated that heuristic intermittent management of the ICE-EG group on series HEV architectures ensures achieving performance significantly close to the optimal ones, resulting in fuel economy as high as $95 \%$ of the optimal values computed via Dynamic Programming [24].

\section{IMPLEMENTATION OF RULE-BASED CONTROL STRATEGY IN LABVIEW}

After proving its suitability for real-time energy management of HSV, the RB strategy was then implemented 


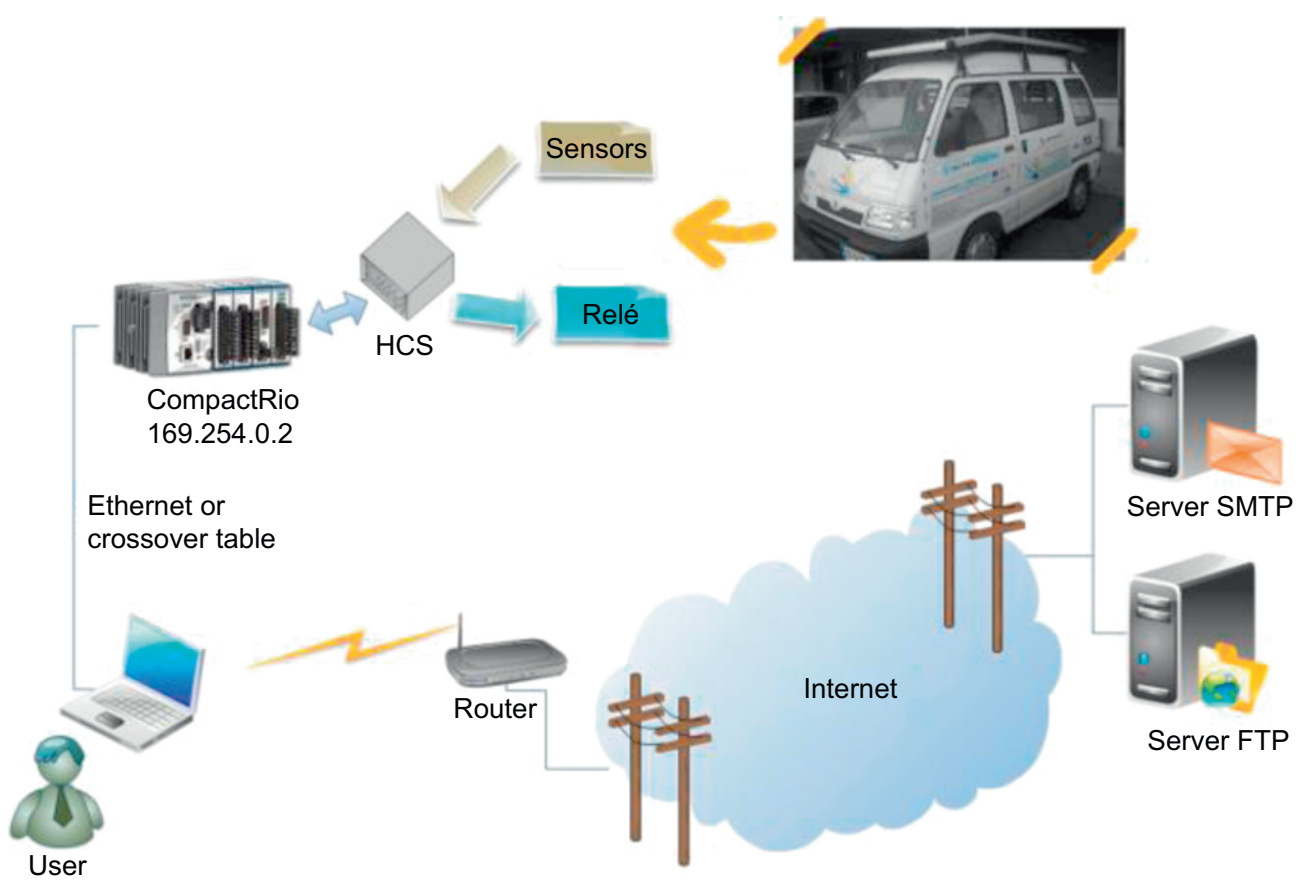

Figure 7

Flow of information for the Real Time application of RB strategy on HSV.

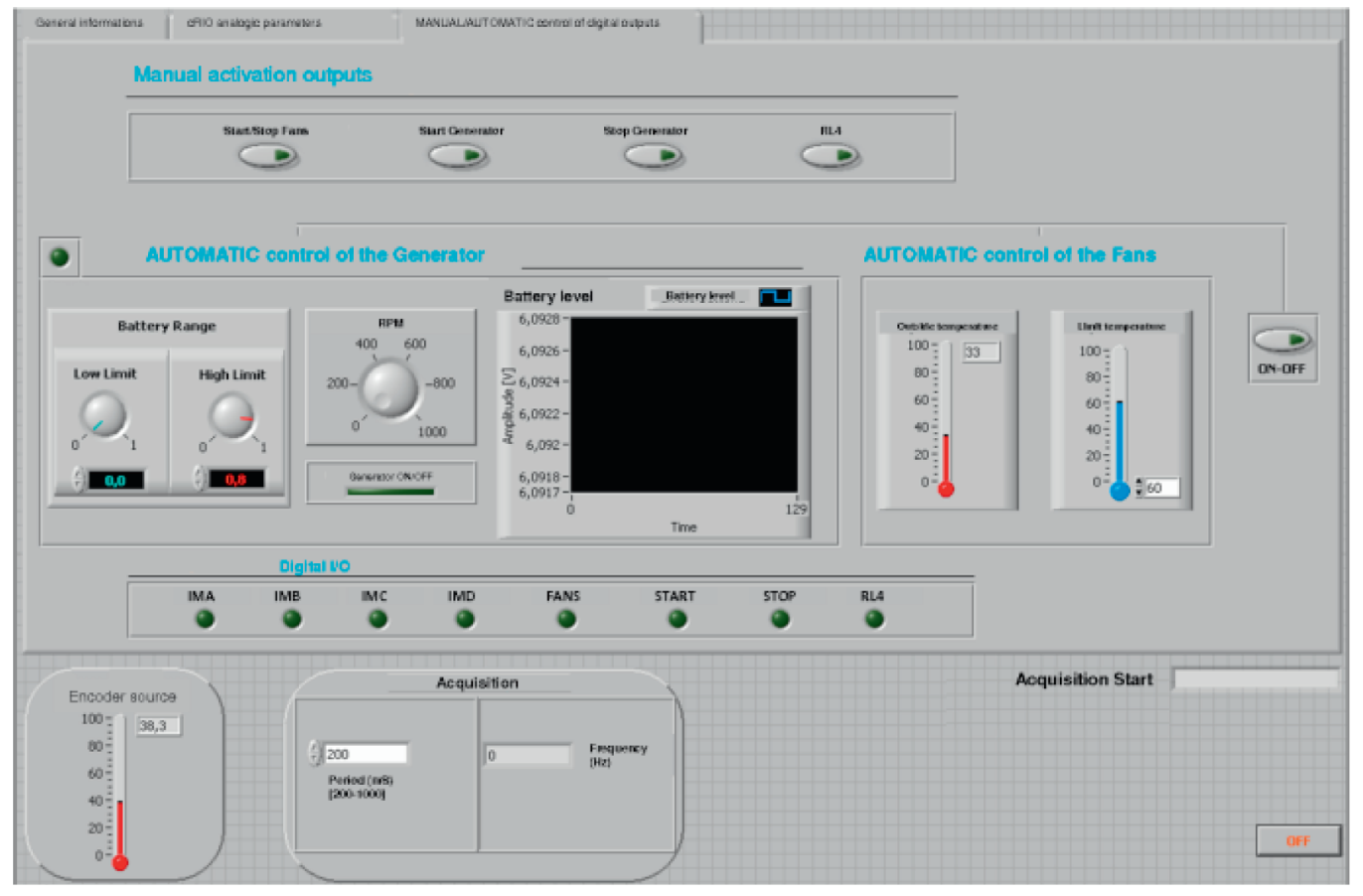

Figure 8

The cRIO interface. 


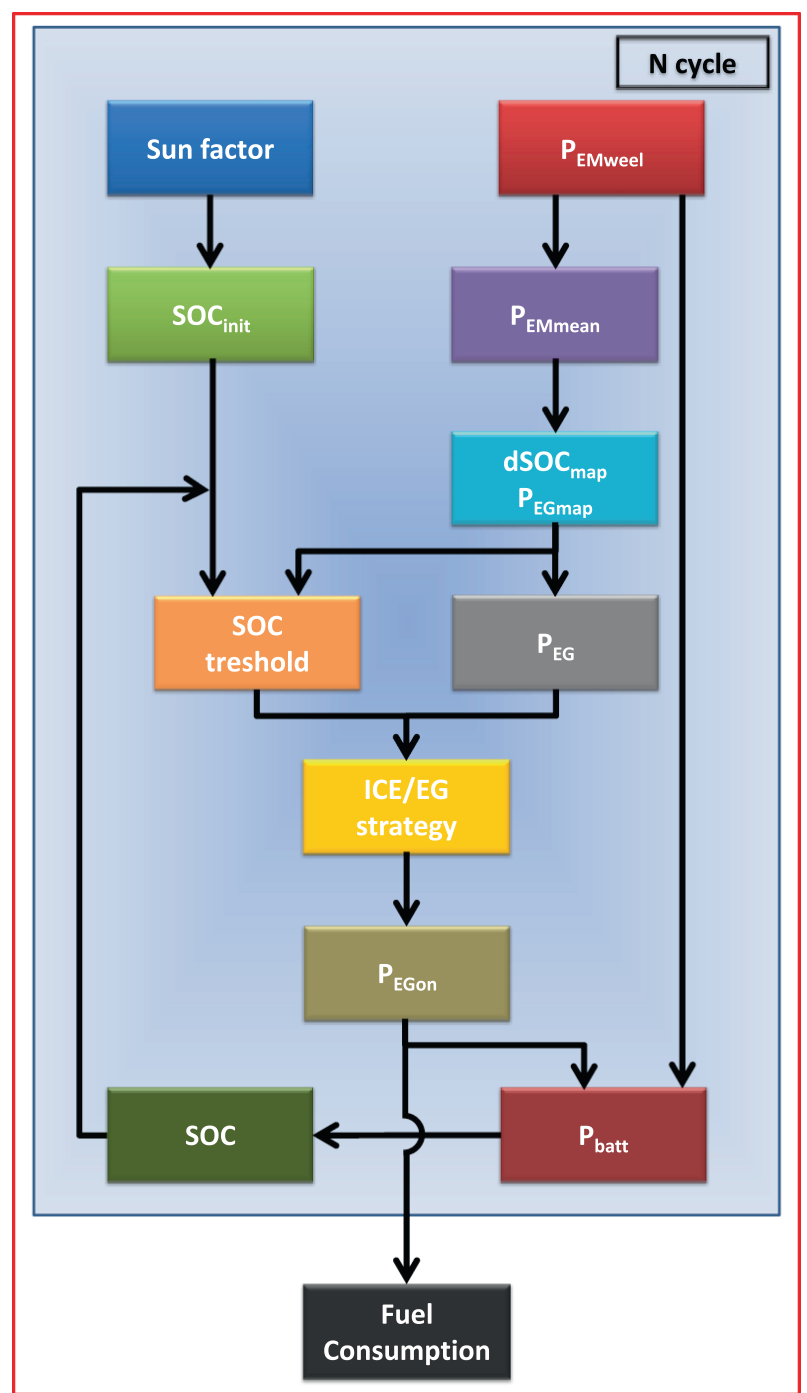

Figure 9

The scheme of the RB strategy implemented into the NI-cRIO platform.

onboard into a National Instrument compact Rio $\left(\mathrm{NI}^{\circledR}\right.$ cRIO) platform, connected to a number of analog and digital $\mathrm{I} / \mathrm{O}$ ports.

The main idea is the Real Time application of RB strategy on the HSV: the flow of information is shown in Figure 7.

The interface between the cRIO platform and the $\mathrm{PC}$ to control manual and digital $\mathrm{I} / \mathrm{O}$ are represented in Figure 8.

Main analog inputs include current, voltage, temperature, speed, angular speed, solar irradiation, torque and pedal position measurements. The digital outputs are mainly applied to electrical switches aimed at effectively performing the control actions addressed by the RB strategy, as shown on the scheme plotted in Figure 9. The main inputs for the on-board RB strategy are:

- $S_{f}$ : sun factor, depending on which the value of $S O C_{f}$ is determined, see Equation (1). $S_{f}$ can be computed on-board as function of sun irradiation measured by a pyranometer or estimated by comparing the actual solar power with its maximum value based on latitude and time;

- $P_{E M}$ : electric motor power $(\mathrm{kW})$, affecting Equations (2) and (3).

An a posteriori strategy is applied online to update every $t_{h}$ seconds the average power requested by the EM to power the wheels $\left(\bar{P}_{E M}\right)$. Then, according to $\bar{P}_{E M}$, the upper and lower SOC thresholds, depending on which ICE intermittency is managed, are evaluated:

$$
\begin{aligned}
& S O C_{\min , \bar{t}}=S O C_{\bar{t}}-d S O C \\
& S O C_{\max , \bar{t}}=S O C_{\bar{t}}-d S O C
\end{aligned}
$$

In order to estimate on-board the current value of battery SOC, the battery model utilized in Matlab ${ }^{\circledR}$ was transferred into LabVIEW environment.

\section{EXPERIMENTAL RESULTS}

The on-board implementation of the RB strategy was tested by running the HSV prototype along the driving route shown in Figure 10 -speed plot. During the test, a time horizon $t_{h}=41.7 \mathrm{~s}$ was imposed to suitably update average EM power. Figure 10 also shows the following measurements: a) SOC and its thresholds; b) speed of the HSV; c) power of Electric Generator; d) traction power, computed starting from the torque measured with a torquemeter; e) electric motor power; and f) mean power of electric motor.

In order to discuss the real operation of RB strategy, the values of SOC, speed, generator power and traction power are analyzed by referring to each section numbered in the figure:

1. in this sections, HSV's speed and power traction are zero, so there is no variation of SOC;

2. there is a strong SOC decrease due to a rapid acceleration from 0 to $10 \mathrm{~km} / \mathrm{h}$;

3. the value of $\mathrm{SOC}$ decreases until the value of $\mathrm{SOC}_{\min }$ (point 3), as imposed by the RB strategy;

4. despite the ICE is on there are two little battery discharges due to two strong accelerations;

5. there is a linear increase of SOC, as a consequence of the almost constant value of traction power; 
a)

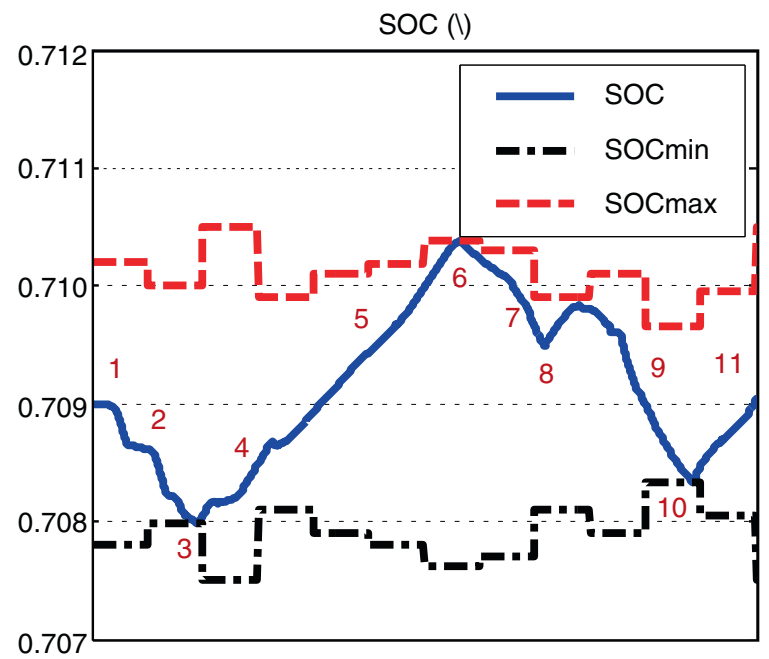

Electric generator power $(\mathrm{kW})$

c)
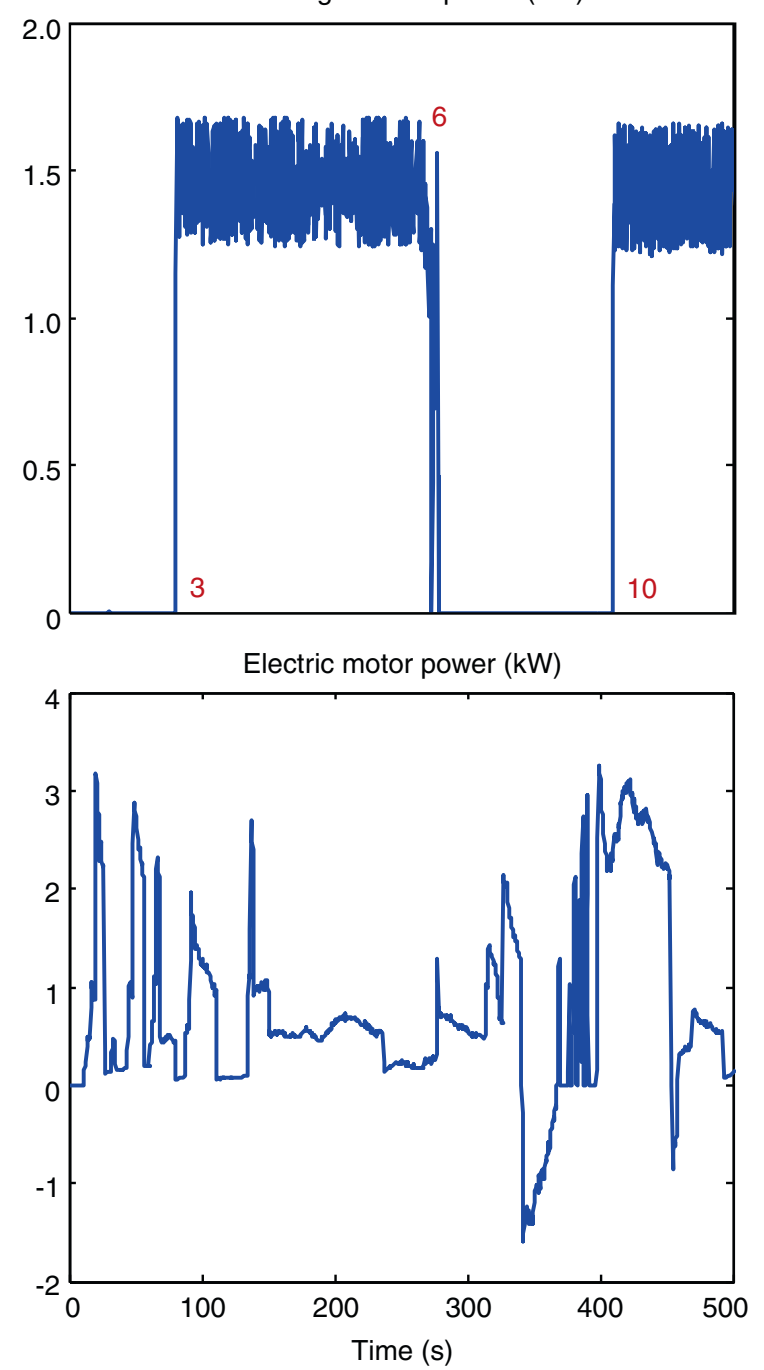

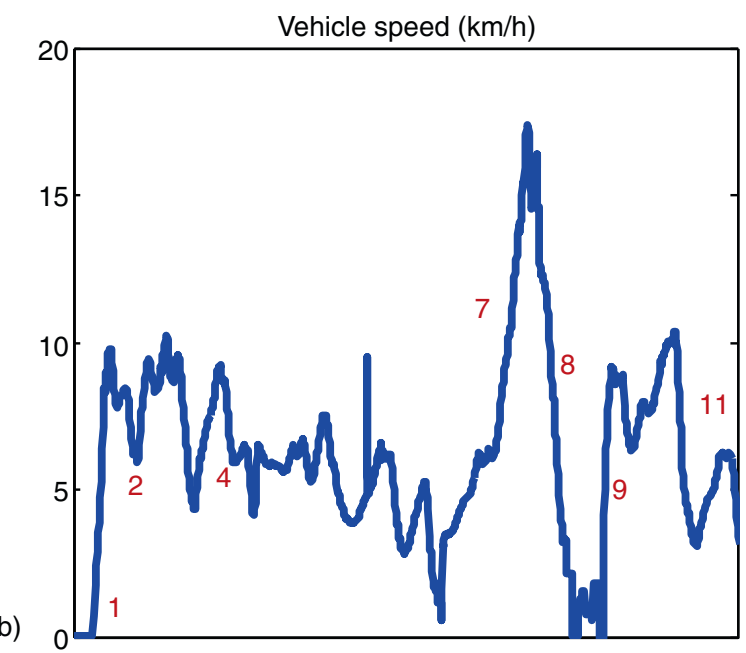

Power at wheels $(\mathrm{kW})$
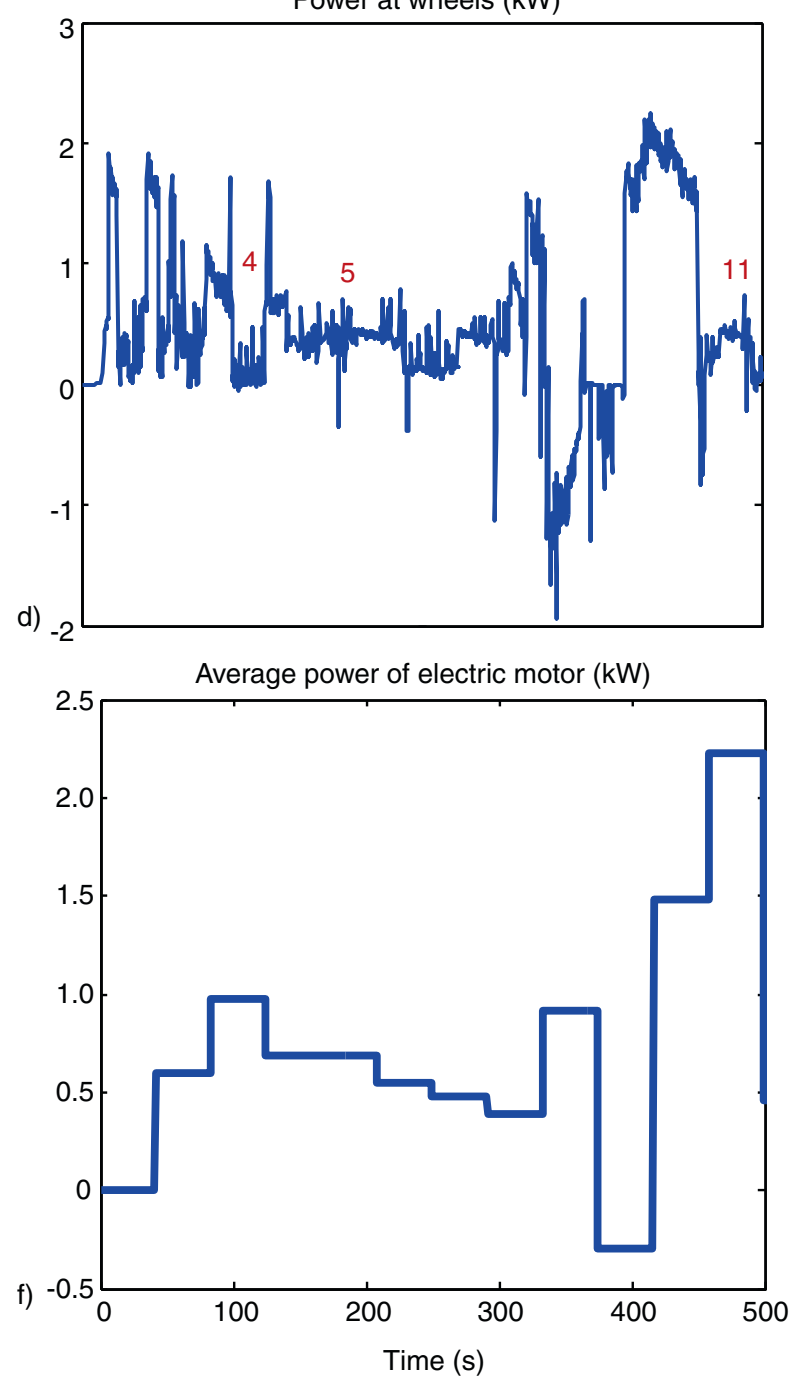

Figure 10

Plots of main acquired variables during the on-board test of RB strategy. a) SOC and its thresholds; b) speed of the Hybrid Solar Vehicle; c) power of Electric Generator; d) traction power, computed starting from the torque measured with a torquemeter; e) electric motor power; and f) mean power of electric motor. 
6. the value of $\mathrm{SOC}$ grows till the $\mathrm{SOC}_{\max }$ (point 6) value imposed by the RB strategy;

7. there is a rapid SOC decrease due to the high acceleration;

8. the ICE is off but there is a brief recharge. This happens because there is a strong braking (regenerative braking) as it is possible to see in the speed plot;

9. the value of SOC decreases again with a strong gradient due to high acceleration;

10. the value of SOC decreases until another value of $\mathrm{SOC}_{\min }$ (point 10) that is imposed by the RB strategy;

11. the speed till the end of the cycle is low and almost constant, so the battery gets smoothly charged back to the initial value, thus guaranteeing overall charge sustaining operation.

Obviously the trends of SOC's thresholds depend on (Figure 10) measurement.

It is worth mentioning that at the current stage it is not possible to fully apply the rule expressed by Equation (2) on-board, due to the features of the battery charger, through which ICE-EG and battery are interfaced, that limits the maximum charging power to about $1.5 \mathrm{~kW}$. This in turn also avoided running the vehicle at speed higher than $18 \mathrm{~km} / \mathrm{h}$, on one hand, and, on the other, did not allow to test the prototype under charge depletion operation to fully evaluate solar contribution. Therefore, the final fuel economy achieved in the realworld cycle shown in Figure 10 was as high as $12.5 \mathrm{~km} / 1$. Such value is $23 \%$ lower than what can be achieved by the rule based strategy, as shown in Figure 6 in correspondence of normal PV contribution (i.e. at sun factor equal to 1). This is of course due to:

- at $1.5 \mathrm{~kW}$ the ICE-EG group works at $18 \%$ efficiency [17, 23];

- charge depletion was not imposed thus excluding the PV contribution during the parking phase;

- Equation (2) was not active.

Nevertheless, the experimental test presented and discussed in the current section has been certainly useful to test the reliability of the developed control algorithm and to overcome the many difficulties encountered when passing from theory to practice in automotive control applications.

\section{CONCLUSIONS}

The paper presents the application of a previously developed Rule-Based control strategy on a prototype of series Hybrid Solar Vehicle developed at the University of Salerno. The strategy, validated in previous papers against results obtained via Dynamic Programming and Genetic Algorithms, has been analyzed via simula- tion analysis, by comparing fuel economy obtained with the application of RB strategy with the results of two extensive parametric analyses.

The RB strategy has been then implemented on the prototype through the development of a LabVIEW algorithm, which was then embedded onto a NI cRIO platform. Preliminary experimental tests have been performed to test the reliability of the control strategy and of the vehicle control system.

Future work will focus, on one hand, on extending the numerical analyses to other driving cycles and/or HSV architecture and, on the other hand, on further testing the correspondence of real fuel consumption measured on the vehicle and the ones obtained by a simulator developed in LabVIEW.

\section{REFERENCES}

1 The Kyoto Protocol, http://unfecc.int/kyoto_protocol/ items/2830.php

2 BP Statistical Review of World Energy 2010.

3 Sciarretta A., Guzzella L. (2007) Control of Hybrid Electric Vehicles, IEEE Control Syst. Mag. 27, 2, 60-70.

4 Vinot S. (2010). The development of hybrid and electric vehicles. Panorama 2010. http://www.ifpenergiesnouvelles. com/content/download/70595/1513798/

5 Pisu P., Rizzoni G. (2007) A Comparative Study of Supervisory Control Strategies for Hybrid Electric Vehicles, IEEE Trans. Control Syst. Technol. 15, 3, 506-518.

6 Rizzo G. (2010) Automotive Applications of Solar Energy, 6th IFAC Symposium Advances in Automotive Control, AAC10, Munich Germany, 11-14, July.

7 REN21, Renewables 2010 Global Status Report.

8 Retail PV costs, www.solarbuzz.com.

9 World Solar Challenge, www.wsc.org.au.

10 Chan C.C. (2002) The state of the art of electric and hybrid vehicles, Proc. IEEE 90, 2, 247-275.

11 Jalil N., Kheir N, Salman M. (1997) Rule-based energy management strategy for a series hybrid vehicle, in Proceedings of the American Control Conference 1997, 4-6 June, 1, 689-693.

12 Baumann B., Washington G., Glenn B., Rizzoni G. (2000) Mechatronic design and control of hybrid electric vehicles, IEEE/ASME Tran. Mechatronics 5, 1, 58-72.

13 Hochgraf C., Ryan M., Weigman H. (1996) Engine control strategy for a series hybrid electric vehicle incorporating load-leveling and computer controlled management, in SAE International Congress \& Exposition, SAE Technical Paper 960230.

14 Brahma A., Guezennec Y., Rizzoni G. (2000) Optimal energy management in series hybrid electric vehicles, in Proceedings of the American Control Conference 1, 60-64.

15 Cipollone R., Sciarretta A. (2006) Analysis of the potential performance of a combined hybrid vehicle with optimal supervisory control, IEEE International Conference on Control Applications, Munich, Germany, 4-6 Oct., 2802-2807. 
16 Letendre S., Perez R., Herig C. (2003) Vehicle Integrated PV: A Clean and Secure Fuel for Hybrid Electric Vehicles, Proc. of the American Solar Energy Society Solar 2003 Conference, Austin, TX, 21-23 June.

17 Adinolfi G., Arsie I., Di Martino R., Giustiniani A., Petrone G. (2008) A Prototype of Hybrid Solar Vehicle: Simulations and On-Board Measurements, AVEC 2008, Kobe Japan, 6-9 Oct., 2008917-922 Society of Automotive Engineers of Japan - ISBN: 978-4-904056-21-9.

18 Rodatz P., Paganelli G., Sciarretta A., Guzzella L. (2005) Optimal Power Management of an Experimental Fuel Cell/Supercapacitor-Powered Hybrid Vehicle, Control Eng. Pract. 13, 1, 41-53.

19 Syed F.U., Kuang M.L., Czubay J., Ying H., Hao Ying (2006) Derivation and Experimental Validation of a Power-Split Hybrid Electric Vehicle Model, IEEE Trans. Vehic. Technol. 55, 6, 1731-1747.

20 Moreno J., Ortúzar M.E., Dixon J.W. (2006) EnergyManagement System for a Hybrid Electric Vehicle, Using Ultracapacitors and Neural Networks, IEEE Trans. Ind. Electron. 53, 2, 614-623.

21 Rizzo G., Sorrentino M., Arsie I. (2009) Rule-Based Optimization of Intermittent ICE Scheduling on a Hybrid Solar Vehicle, SAE Int. J. of Eng. 2, 2, 521-529.

22 Walsh P.M. (2011) Plug-in Hybrid Electric Vehicle Supervisory Control Strategy Considerations for Engine Exhaust Emissions and Fuel Use, PhD Thesis, Virginia Tech, May 2011.
23 Sorrentino M., Arsie I., Di Martino R., Rizzo G. (2010) On the Use of Genetic Algorithm to Optimize the On-board Energy Management of a Hybrid Solar Vehicle, Oil \& Gas Sci. Technol. - Revue de l'IFP 65, 1, 133-143.

24 Sorrentino M., Rizzo G., Arsie I. (2011) Analysis of a RuleBased Control Strategy for On-Board Energy Management of Series Hybrid Vehicles, Control Eng. Pract. 19, 14331441 .

25 Coraggio G., Pisanti C., Rizzo G., Sorrentino M. (2010) Assessment of benefits obtainable in a Hybrid Solar Vehicle using look-ahead capabilities for incoming solar energy, Proc. of 10th International Symposium on Advanced Vehicle Control AVEC10, Loughborough, UK, 22-26 Aug. Loughborough University Dept. of Aeronautical \& Automotive Engineering \& Transport Studies, -ISBN 9780904947656.

26 Rizzo G., Sorrentino M. (2010) Introducing Sunshine Forecast to Improve On-Board Energy Management of Hybrid Solar Vehicles, Proc. of 6th IFAC Symposium Advances in Automotive Control, AAC10, 11-14 July, Munich, Germany.

27 Arsie I., Graziosi M., Pianese C., Rizzo G., Sorrentino M. (2005) Control Strategy Optimization for Hybrid Electric Vehicles via Provisional Load Estimate, Review of Automotive Engineering, ISSN 1349-4724, Japanese Society of Automotive Engineers Review, JSAE Rev. 26, 341-348.

Final manuscript received in December 2012

Published online in April 2013 made or distributed for profit or commercial advantage and that copies bear this notice and the full citation on the first page. Copyrights for components of this work owned by others than IFP Energies nouvelles must be honored. Abstracting with credit is permitted. To copy otherwise, to republish, to post on servers, or to redistribute to lists, requires prior specific permission and/or a fee: Request permission from Information Mission, IFP Energies nouvelles, fax. +331475270 96, or revueogst@ifpen.fr. 